\title{
DE FARDOS QUE PODEM ACOMPANHAR A ATIVIDADE DOCENTE OU DE COMO O MESTRE PODE DEVIR BURRO (OU CAMELO)
}

\author{
Sylvio de Sousa Gadelha Costa*
}

\begin{abstract}
Burro (ou Camelo) - São os animais do deserto (niilismo). Carregam, carregam com fardos até o fim do deserto. O Burro tem dois defeitos: o seu Não é um falso não, um "não" do ressentimento. E, ainda mais, o seu Sim (...) é um falso sim. Julga que afirmar significa carregar, assumir. O Burro é, em primeiro lugar, o animal cristão: carrega com o peso dos valores ditos "superiores à vida". Depois da morte de Deus, carrega-se a si mesmo, carrega com o peso dos valores "humanos", pretende assumir "o real como ele é": por conseguinte, ele é o novo Deus dos "homens superiores". De uma ponta à outra, o Burro é a caricatura e a traição do Sim dionisíaco; afirma, mas só afirma os produtos do niilismo. As suas longas orelhas opõem-se, pois, às orelhas pequenas, redondas e labirínticas de Dioniso e de Ariana.
\end{abstract}

(Gilles Deleuze, 1990, p. 30)

RESUMO: O texto explora, desdobra e mesmo força alguns dos traços e contornos ligados ao mal-estar que acompanha os educadores contemporâneos, para depois, em seu desfecho, reconduzir o leitor a uma possível e breve interpretação a partir do "duplo" DeleuzeNietzsche. O sentido é tornar visíveis alguns processos e sintomas implicados na produção desse mal-estar, bem como a lógica que o anima. Assim, quem sabe, com essa rápida sinalização, este escrito possa dar o que pensar sobre a questão: como fazer da educação um problema, movimentando-a, inquietando-a, abrindo-a a novos possíveis, a novas experimentações e desafios.

Palavras-chave: Mal-estar docente. Deleuze. Nietzsche.

Doutor em educação e professor da Universidade Federal do Ceará (UFC).

E-mail: sylviogadelha@uol.com.br

Educ. Soc., Campinas, vol. 26, n. 93, p. 1257-1272, Set./Dez. 2005

Disponível em <http://www.cedes.unicamp.br> 
De fardos que podem acompanhar a atividade docente ou de como o mestre...

\title{
OF HOW BURDENS CAN BE LAID ON TEACHING ACTIVITY OR HOW A TEACHER CAN BECOME A DONKEY (OR A CAMEL)
}

\begin{abstract}
This paper explores, unfolds and in a sense stretches some of the traces and contours which could be connected to the malaise associated with contemporary educators. It then tries to lead the reader back to a possible and brief interpretation based on the "double" Deleuze-Nietzsche. It is intended to make visible some of the processes and symptoms implied in the production of this malaise, as well as to explicit the logic that gives life to it. These modest hints hope to force us to think about the following question: how can we transform education into a problem? Which, in turn, may put education in motion, disrupt it and open it up to new possibilities, experimentations and challenges.
\end{abstract}

Key words: Teacher's malaise. Deleuze. Nietzsche.

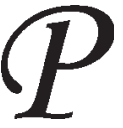

or força da necessidade, logo depois de iniciar meus estudos universitários em psicologia, assumi a função de professor numa escola pública na periferia pobre de Fortaleza. Nesses anos de magistério, vividos numa realidade consideravelmente diversa daquela que encontrei na UFC, em meio à miséria, à violência, à ignorância, à falta de recursos, vi-me progressivamente tomado por um intenso e paradoxal malestar: por um lado, surpreendeu-me observar quanto os educadores pareciam pessoas cansadas, esgotadas, consumidas, esvaziadas de suas potências, anos a fio, pela mesmice de seu cotidiano institucional, por suas condiçóes de vida e pelas adversidades (baixos salários, falta de apoio, abandono) que marcavam o exercício de sua profissão; por outro lado, causava-me impressão o quanto esses mesmos educadores estavam como que banhados, prática e discursivamente, por uma cultura e um ativismo político-academicista que, seja à direita ou à esquerda, valorizando e exaltando sua importância social quer para o desenvolvimento e o progresso da nação (liberal-democratas), quer para uma incerta revolução (marxista-leninistas), além de revestirem sua missão educativa de dignidade, honradez e humanismo, os responsabilizavam diretamente pela imensa e grandiosa tarefa de fazer do Brasil o "País do Futuro".

Ora, a suspeita de que esses educadores introjetavam e faziam seus os contraditórios e ambíguos princípios, valores e imperativos emanados por esse misto efusivo de cultura, ideário e ativismo político-academicista, somada ao fato de que eles continuavam a sofrer concretamente os efeitos 
perversos de suas condições de vida e trabalho, levava-me a pensar, ainda que incipientemente, que o exercício da profissão docente, pelo menos na esfera pública, parecia atravessado por certa esquizofrenia, suscitando desorientação, sofrimento e desamparo. Assim, entre o imperativo de o professor conscientizar-se como educador, cidadão e revolucionário, e sua difícil e grandiosa tarefa emancipadora, instalavam-se a dor e a angústia, algo crivado por certa crueldade.

Nos anos seguintes, transcorridos em São Paulo, dividido entre a docência num estabelecimento de ensino superior e atividades profissionais voltadas ao atendimento à "menor-idade", pude me aperceber de que, guardadas algumas diferenças, o inquietante mal-estar anteriormente descrito parecia também se fazer presente entre os "profissionais do social", ou seja, entre uma série de trabalhadores mais ou menos qualificados que desenvolviam suas ações em instituições, entidades e programas - governamentais e não-governamentais - voltados para o "campo" da assistência social. Embora estes não desempenhassem estritamente funções e tarefas tipicamente da alçada dos professores, a não ser quando ministravam treinamentos, oficinas, organizavam grupos comunitários e outros congêneres, é inegável que suas atividades guardavam um caráter formativo-educativo, tornando às vezes difícil diferenciá-los daqueles.

Poder-se-ia argumentar, com razão, que o denominador comum desse paradoxal mal-estar (que afeta tanto educadores como esses outros profissionais) residiria no fato, eminentemente político, econômico e social, de ambos constituírem categorias profissionais "destacadas" pela sociedade para lidarem, como linha de frente, com a dura realidade da miséria, da violência e da exclusão, bem como com seus perversos efeitos. Pense-se, por exemplo, o que significa ter de conviver, durante um tempo considerável - sem remuneração adequada e, amiúde, sem o auxílio de condições materiais e técnicas satisfatórias -, com dificuldades tais como: fome, prostituição infantil, grupos de extermínio, violência doméstica, problemas com drogas, alcoolismo, analfabetismo, desemprego, brigas de gangues, assaltos e latrocínios, falta de saneamento básico, péssimas condiçôes de vida em favelas e cortiços, carência de outros equipamentos sociais etc. Pense-se, por exemplo, atendo-me estritamente ao atendimento institucional à "menor-idade", na difícil condição dos profissionais que atuam nas FEBEMs - entre os quais muitos são pedagogos e professores -, particularmente daqueles que atuam com os adolescentes que cometeram atos infracionais. Pois bem, poucos deles têm como fazer 
De fardos que podem acompanhar a atividade docente ou de como o mestre...

uma gestão salutar de seus "vínculos institucionais com o abandono", como bem salientou Marlene Guirado (Guirado, 1986).

Nessa perspectiva, educadores e profissionais do social teriam suas vidas e atividades profissionais atravessadas pelo sofrimento, e este, por seu turno, em última instância, seria explicado pela má distribuição de riquezas num país como o nosso, fruto de um modelo de desenvolvimento dependente e concentrador de renda, submetido às exigências das agências de financiamento do mercado transnacional capitalista. Em outros termos, educar, formar e assistir, tendo em vista a realidade apontada, constituiriam atividades profissionais crivadas por dificuldades e pelo desgaste; atividades estas, portanto, que implicariam "carregar fardos". E tais infortúnios e fardos, por sua vez, seriam determinados basicamente por motivos de ordem política e econômica. Não discordo totalmente da pertinência desse tipo de leitura, no entanto creio que ela não só não dá conta de uma série de outros fatores relevantes agenciados à questão do mal-estar anteriormente evocado como também - quando, e se os reconhece como reais e atuantes - insiste em deixá-los à sombra, minimizando-os.

Assim, o que me proponho neste texto consiste basicamente em explorar, desdobrar e mesmo forçar alguns dos traços e contornos ligados a esse mal-estar, para depois, em seu desfecho, reconduzir o leitor a uma possível e breve interpretação da epígrafe que lhe serve de gatilho. $\mathrm{O}$ duplo Deleuze/Nietzsche, então, é aí discretamente convocado como escuta crítica e clínica capaz de contribuir para tornar visíveis alguns processos e sintomas outros implicados na produção desse mal-estar, bem como a lógica que o anima. Talvez, quem sabe, com essa rápida sinalização, este escrito possa dar o que pensar acerca de como ambos (Nietzsche e Deleuze) podem fazer problema à educação, movimentando-a, inquietando-a, abrindo-a a novos possíveis, a novas experimentações e desafios.

Dos valores superiores que animam a missão civilizadora da educação

A educação perfaz um campo transinstitucional de práticas e saberes sobre o qual parece pesar uma singular gravidade: por meio de acontecimentos como a Reforma Protestante, a Contra-Reforma, o Iluminismo, a Revolução Francesa - na qual se consagrou a defesa pela generalização da instrução pública - e a Revolução Industrial, ela encampou e traduziu tanto o ideal de uma missáo civilizadora como o de uma empresa demasi- 
ado pretensiosa, grandiosa. Grosso modo, o ideal dessa missão civilizadora se definiria por um duplo intuito. Primeiro, o de levar ao "outro" - supostamente idealizado como designando uma posição de carência ou de falta, e, portanto, significado negativamente (Todorov, 1993) - aquilo que quem se auto-atribui a denominação de "educador"/ "civilizador" acreditaria que detém. Mas não só; trata-se de algo que viria recobrir ou compensar justamente aquela condição de carência ou falta, entendida, $a$ priori, como característica inerente ao "outro". Ora, tal intenção compensatória, materializada num determinado tipo de ação (pedagógica), implicaria, pois, que aquele que "educa"/“civiliza” se supõe detentor de um saber e de um poder sobre o "outro". "Instrumentos", "tecnologias" estes capazes de, uma vez bem operados, torná-lo diferente do que se presumia que ele era. Núbia Pérez de Lara e Jorge Larrosa apontam-nos o efeito dessa operação, ao abordarem a relação com a alteridade na educação contemporânea:

(...) somos nós que definimos o outro, especialmente quando essa nossa definição se supõe avalizada pelos aparatos que articulam uma função técnica ou perita dos distintos campos do saber; somos nós que decidimos como é o outro, o que é que lhe falta, de que necessita, quais são suas carências e suas aspiraçôes. E a alteridade do outro permanece como que reabsorvida em nossa identidade e a reforça ainda mais; torna-a, se possível, mais arrogante, mais segura e mais satisfeita de si mesma. (Lara \& Larrosa, 1998, p. 8)

Curiosamente, ao querer transformar o "outro", assinalando uma diferença (para "melhor", para "mais") com relação à sua "condição original", essa ação educativa funcionaria de tal modo que o converteria à imagem e semelhança de quem o educa. Neste sentido, o grau de assemelhamento conseguido ao cabo dessa peculiar relação, na qual quem educa se auto-institui como modelo exemplar a ser reproduzido, imitado, tornarse-ia aparentemente o critério decisivo para a avaliação do sucesso ou insucesso dessa ação. $\mathrm{O}$ assemelhamento, então, emergiria como condição para o reconhecimento do "outro" e de sua aprendizagem. Nestes termos, a "diferenç" operada sobre o "outro" viria marcada pelos signos paradoxais de uma positividade e de uma negatividade: ser-lhe-ia benéfica, desde que se sujeitasse ao processo de modelização a ele dirigido. Em contrapartida, o caráter paradoxal desse processo parece desfazer-se, na medida em que, uma vez convertido o "outro" numa "boa" imagem (anuindo à submissão), supostamente semelhante ao modelo que lhe ser- 
De fardos que podem acompanhar a atividade docente ou de como o mestre...

viu de referência, isso, todavia, não viria garantir ao primeiro um estatuto de igualdade com relação ao segundo. Ao contrário, esse processo de modelização dissimularia uma operação de pseudo-assemelhamento na qual, em última instância, impera uma dissimetria, ou melhor, uma relação de forças presidida pela hierarquia entre modelo e imagem (cópia): esta é sempre segunda com relação àquele, visto que sua qualificação como "boa" é tributária de uma participação eletiva cuja condição reside na submissão. É sob tais condições, por exemplo, que, no romance de Daniel Defoe, Sexta-Feira tornar-se-ia, enfim, digno do reconhecimento de Robinson Crusoe:

Robinson, apesar de seu etnocentrismo puritano, reflete sobre o canibalismo que tanto (o) aborrece. E ainda que não o justifique, chega a pensar que Deus, em sua infinita sabedoria, terá tido suas razóes para inculcar nesses homens tais costumes. Estamos longe da defesa da pureza primitiva de Rousseau e Diderot, mas, dentro de seu sentimento de superioridade, Robinson admite que Sexta-Feira é a encarnação da inocência, e se pergunta por que Deus não iluminou estes primitivos com sua graça, sendo estes melhores do que os cristãos europeus.

No entanto, em sua relação com Sexta-Feira, Robinson exerce outro tipo de canibalismo: a antropofagia cultural, visto que não concebe outra forma de redenção de seu selvagismo que não seja sua assimilação à cultura européia. Sexta-Feira terminará sendo uma espécie de macaco adestrado digno de seu afeto. (Cavestany, 1998, p. 118, grifo meu)

Bem, se tomarmos como referência, como palco de acontecimentos ou como cenário principal das ações, o início do que se convencionou chamar de "modernidade", na história da civilização ocidental, que personagens encarnariam as figuras do "educador"/"civilizador" e do "outro"? E o quê, com efeito, deveria ser transmitido do primeiro ao segundo, de modo que este viesse a se tornar uma imagem a mais perfeita possível daquele, garantindo assim o "sucesso" da ação educativa/civilizatória?

A figura do "educador" seria encarnada por uma cultura européia humanizada que celebrava a emergência de um novo homem. Um homem que se pensava e que se queria individualizado, racional, livre, esclarecido, empreendedor. Um indivíduo que, embora ainda muito sensível aos valores e à moral do Deus cristão e de sua igreja, atrevia-se a contrariá-los, desvendando e dominando os segredos de um universo cada vez menos divinizado, tornado infinito pelo conhecimento que então se passava a ter da matemática e da geometria. Um homem que, por 
intermédio de novas leis e das instituições, acreditava ter encontrado uma base racional e sólida, garantidora de uma sociabilidade justa e fraterna entre seus pares. Um homem, enfim, que, de tão vaidoso de si, de seus conhecimentos, valores, técnicas, e de sua ciência, queria estender-se e estendê-los para além de seu velho continente, até as "novas" terras, domínios e povos com os quais passava a ter contato, por meio de suas audaciosas navegações e de sua irrefreável sede de riquezas.

O "outro", por sua vez, seria essa estranha e ambígua figura do "selvagem", habitante dos trópicos, que tanto encantava e causava espanto aos primeiros viajantes europeus que por aqui chegaram, com sua "ingenuidade", sua "pureza", sua "indolência", sua vida dita "primitiva", sua "falta de pudor", sua "preguiça", suas crenças e costumes exóticos etc. O "outro" seria tupi, seria guarani, mas também seria maia e asteca. E, ain$\mathrm{da}$, os aborígines australianos, os negros do Continente Africano, os árabes e sarracenos, ou mesmo estranhos povos do Oriente, versões outras da alteridade. Digamos, em suma, que talvez ele pudesse ser encarnado emblematicamente por Sexta-Feira: como o "outro" (de Robinson) a ser (por este) "educado"/"civilizado".

Mas, então, o que deveria ser transmitido por intermédio dessa ação educativa? Tratava-se de todos os elementos e valores que davam condições de possibilidade à emergência desse novo homem europeu e de todas aquelas qualidades que o consubstanciavam como sujeito portador de uma identidade, de uma moral - cristã, mas também utilitarista -, sujeito de direitos e deveres, sujeito do conhecimento, livre e autônomo etc. No entanto, o conteúdo da transmissão envolveria algo mais do que isso: ele encarnaria a possibilidade mesma de fundamentar a realização última do homem, ou seja, a edificação de uma civilização plena, acabada, emancipada, orgulhosa de suas conquistas. Esta se fazia representar e enaltecer, por exemplo, desde o século XVIII, com o Iluminismo, pela firme crença na razão esclarecida e tornada crítica, pelo imperativo da construção de uma liberdade moral e, com Hegel, pelo espírito absoluto e o fim da história. Mas, além disso, com o Positivismo do século XIX, pela aposta otimista num desenvolvimento orientado pela ordem e pelo progresso, por meio da racionalização da vida social e da instrumentalização utilitarista da razão.

Caracterizados o educador e seu "outro" (o que hoje se designa por "sujeito da educação"), resta ainda indagar que imagens daí nos foram legadas acerca do que seja ensinar e aprender, imagens estas cuja produ- 
De fardos que podem acompanhar a atividade docente ou de como o mestre...

ção, inclusive, é parte significativa de um agenciamento mais amplo e complexo que deu condições de possibilidade para que essa relação (educador/educando) fosse possível de ser pensada e exercitada. Muito sucintamente, ensinar seria "passar adiante", transmitir, tal e qual, o que anteriormente já havia sido pensado, "descoberto", feito, cultivado e praticado por outros homens, por suas instituições, pela cultura etc., em suma, tudo aquilo que, nestes termos, teria assumido o sentido de exemplar, modelar. A aprendizagem, por seu turno, estaria vinculada à recognição, isto é, ao reconhecimento e à repetição do que havia sido ensinado, transmitido. Assim, tanto a prática do ensino quanto a prática da aprendizagem foram associadas à reprodução e à repetição do mesmo, do igual, do semelhante.

Se o primeiro dos intuitos da missão civilizadora da educação era a tarefa na qual se devia "dar a partilhar" com o "outro" as condições de que este supostamente necessitaria para ascender a um patamar mais elevado no processo de hominização, o segundo de seus intuitos, por sua vez, foi o de proceder à sua universalização. Nessa perspectiva, a tarefa educativa deveria ser propagada, deveria ser levada homogeneamente a todos os lugares e povos com quem esse homem "civilizado" travava contato. Isto é, a educação, entendida nestes termos e desde este ponto de vista, deveria ser universalizada, tornada una. Contudo, esse intuito logo se mostrou uma empresa das mais difíceis e complicadas. E isso em razão de uma série de fatores, particularmente pelos seguintes: a) pelo fato de o "outro" logo se revelar resistente e equivoco em face das investidas que lhe eram dirigidas. Sexta-Feira, no final das contas, jamais encarnou efetivamente o papel de "macaco amestrado" (boa cópia), assim como tampouco jamais se mostrou carente de um reconhecimento por parte de Robinson, para ira e surpresa deste. Na verdade, a alteridade, com suas peculiaridades, com suas irredutíveis diferenças, com seus estranhos modos de agir, pensar e sentir, na singular maneira como se conecta ao tempo e ao espaço, nas formas como concebe o profano e o sagrado, sempre foi motivo de desconcerto e desconfiança (misto de encanto e paranóia) para os ditos "educados/civilizados" (para um sentido da alteridade ao de Robinson Crusoe, cf. Tournier, 2001; Deleuze, 1998); b) em decorrência disso, uma vez constatado o fato de que a relação "educador/educando" seria atravessada por conflitos que lhes seriam imanentes, o processo civilizatório-educacional desenvolveu-se sempre, e necessariamente, sob o signo do embate, do jogo de forças e da tentativa de dominação. É 
fácil imaginar, pois, os incomensuráveis esforços que essa missão, colocada sob encargo dos professores, demandaria para ser levada a bom termo, assim como os inúmeros e consideráveis obstáculos que precisaria superar a fim de ver-se, um dia, universalizada - o que, afinal de contas, jamais aconteceu. É sob esse prisma que a grandiosa tarefa da educação, universalizar a civilização e a emancipação, hoje se nos aparece como fantasiosa e frustrada pretensão do projeto de liberação constituído e encampado na e pela modernidade.

\section{De como esses valores superiores se convertem em fardos}

De qualquer forma, à medida que esse projeto se pôs em andamento, a educação terminou por firmar-se como uma das principais instituiçōes das sociedades ocidentais na modernidade. Numa palavra, a educação, num sentido amplo, e, mais especificamente, a escola pública instituíram-se como lugares privilegiados de investimento de expectativas sociais, isto é, lugares "em que, por excelência, a sociedade se vê com os olhos da antecipação" (Valle, 1997, p. 12). Suas finalidades, seu papel, suas aplicações no campo da cultura e da produção, seus agentes, suas modalidades de exercício, normas, formas de organização e tecnologias, foram como que banhados por um conjunto de significados, social e historicamente constituídos, imbuídos de uma forte positividade, agenciando-se com destaque na construção da ordem simbólica e cultural dominante no Ocidente.

É assim que, em nossa sociedade, "ser professor", "educar" e "formar educadores", por exemplo, tornaram-se atividades, à primeira vista, valorizadas socialmente, ou seja, significadas como dignas e importantes. Dir-se-ia, mesmo, que seriam atividades fundamentais para o presente e o futuro dos homens. Observa-se, pois, uma valorização tal desse "quefazer" pedagógico que, sob os ombros dos profissionais da educação, terminaria por pesar uma enorme responsabilidade moral: a de civilizar uma vila, uma coletividade, uma cidade, um estado, um país e, em nossos dias, todo um mundo que inexoravelmente se globaliza.

É dessa maneira, pois, que, em face de sua desmedida missão civilizadora, a tarefa de educar parece ter assumido uma extrema gravidade, podendo-se facilmente associar o educador à figura de um soldado e de um salvador. E, no entanto, não seria menos correto associá-lo também à figura de um carregador de fardos: tanto voluntarismo, tanta abnegação, 
De fardos que podem acompanhar a atividade docente ou de como o mestre...

tanta renúncia e, por que não dizer, tanta culpa... Com efeito, é digno de nota, quando as coisas não vão bem nas searas da educação, o quanto se costuma imputar aos professores - alegando-se da parte deles apatia, despreparo, ineficiência, desinteresse ou mesmo falta de civismo - boa parte das responsabilidades aí implicadas. Como - é o que se lhes aponta - não fazem jus à nobre missão de que foram investidos? Como, a despeito das imensas dificuldades que cercam sua grandiosa tarefa, podem eles furtar-se a ela? Para que melhor se entenda esse desconforto a que estão sujeitos os professores, faz-se necessário assinalar, como o faz Cambi (1999), que o mundo moderno se viu constantemente atravessado por uma "profunda ambigüidade", cuja presença se fez notar especialmente no âmbito da educação. Trata-se da antinomia por meio da qual se oscilou, inquietantemente, de um passo a outro, entre dois movimentos opostos: o de liberalização e o de governamentalidade (minucioso controle social dos corpos-subjetividades). Com efeito, para Cambi, o mundo moderno...

(...) pretende libertar o homem, a sociedade e a cultura de vínculos, ordens e limites, fazendo viver de maneira completa esta liberdade, mas, ao mesmo tempo, tende a moldar profundamente o indivíduo segundo modelos sociais de comportamento, tornando-o produtivo e integrado. Trata-se de uma antinomia, de uma oposição fundamental que marca a história da Modernidade, faz dela um processo dramático e inconcluso, dilacerado e dinâmico em seu próprio interior, e portanto problemático e aberto. (1999, p. 200)

Ora, talvez mais do que nenhuma outra, a profissão de professor (particularmente daquele que atua com a educação infantil e o ensino fundamental e médio) encarne socialmente, e veja-se obrigada a suportar, para seu infortúnio, essa dilacerante ambigüidade entre emancipação (pela liberalização) e governo (pelo controle). A presença deste, embora subsumida pela exaltação em torno daquela, não deixa de se fazer sentir por meio de tabus e preconceitos. Como assinalou Theodor Adorno, certo desprestígio, um "silencioso ódio", rondaria os professores não-universitários, atormentando-os. A fim de melhor expressá-lo, não me deterei no que Adorno considera suas motivaçóes profundas, mesmo porque elas se enraizariam em especificidades da história da cultura alemã e da Europa anglo-saxônica. Assim, passo diretamente às suas considerações de alcance mais amplo. Os professores, na qualidade de "estudados", ou seja, na condição de executores de um trabalho de natureza intelectual, teri- 
am sido objeto de uma transferência social negativa, outrora reservada aos monges religiosos. A profissão de professor, à diferença de outras profissões intelectuais "livres" (juristas e médicos), subordinadas à disputa concorrencial, providas de melhores oportunidades materiais - o que lhes angariaria certo prestígio - e relativamente autônomas em face da regulamentação e da hierarquia que ordenavam o serviço público, seria formada de profissionais que, a despeito de sua segurança e estabilidade, estariam sujeitos a uma série de obrigações e impedimentos, assemelhando-se estes a "verdadeiros animais de carga em escritórios e repartições, com horários fixos e vida regrada pelo relógio de ponto" (Adorno, 2000, p. 103). Além disso, diferentemente de juízes e funcionários administrativos, investidos de algum poder real diante da opinião pública, o poder do magistério ver-se-ia esvaziado e alvo de chacotas por exercer-se fundamentalmente sobre os enfants, os "sem-palavra", portanto apenas sobre quase-sujeitos civis.

O poder do professor é execrado porque só parodia o poder verdadeiro, que é admirado. Expressóes como "tirano da escola" lembram que o tipo de professor que querem marcar é tão irracionalmente despótico como só poderia sê-lo a caricatura do despotismo, na medida em que não consegue exercer mais poder do que reter por uma tarde as suas vítimas, algumas pobres crianças quaisquer. (Idem, ibid., p. 103-104)

A condição esquizofrênica a que são submetidos os professores, tendo que se haverem ao mesmo tempo com os imperativos de uma tarefa emancipadora e de uma função disciplinadora, caracteriza-se, entre outros aspectos, pela incerteza, pela desconfiança e por certo rebaixamento de seu status social. Na lógica que move as sociedades disciplinares problematizadas por Foucault, em que o emprego da força física não só pode como deve ser dissimulado, os professores são justamente aqueles a quem se delega a preciosa função "educativo-civilizadora". Mas essa tarefa, segundo Adorno, traz paradoxalmente consigo o estigma de ser um "trabalho sujo":

Uma parte constitutiva essencial deste complexo parece estar em que a sociedade que se apresenta como liberal-burguesa em hipótese nenhuma reconhece a necessidade da força física para uma formação social baseada na dominação. Isso ocasiona tanto a delegação da violência - um senhor jamais castiga - quanto o desprezo pelo professor que se encarrega de executar o que é necessário para tudo funcionar, sabidamente um mal 
De fardos que podem acompanhar a atividade docente ou de como o mestre...

que é duplamente rejeitado pelas pessoas, na medida em que elas próprias estão por trás da execução, e ao mesmo tempo se julgam boas demais para executá-la pelas próprias mãos. A minha hipótese é de que a imagem de "responsável por castigos" determina a imagem do professor muito além das práticas dos castigos físicos escolares. (2000, p. 107)

Por fim, vale a pena lembrar de outra questão levantada por Adorno, esta referente a toda uma erótica peculiar ao magistério. Aqui, em virtude de sua singular posição ante os alunos, a instituição educativa e a sociedade, em razão da "idéia do docente com a vida inquestionável como modelo", o professor ver-se-ia compelido a exercitar uma dura e problemática ascese erótica, no transcurso da qual terminaria por assumir a imagem de um excluído do desejo, de um ser neutralizado no plano desejante. Curiosamente, passado pouco mais de um século desde a criação da psicanálise, é surpreendente observar como um sem-número de professores ainda desconhece as vicissitudes do desejo e do inconsciente, os problemas relativos às relaçóes transferenciais, as singularidades da sexualidade infantil, entre outros desenvolvimentos produtivos de Freud. E, no entanto, apesar desse alheamento em face das formulações capitais da psicanálise, não concorreria também ela própria para fazer do magistério uma profissão impossível, talvez não tanto nos termos ou pelas razões por ela alegadas, senão por acrescentar mais fardos (Édipo, falta, castração) ao seu exercício? A vida, as alegrias, mas principalmente os dilemas, as angústias e o sofrimento de professores são rebatidos para uma cena teatral: o professor vai para a sala de aula, acompanhado de papai e mamãe, ou por seus respectivos fantasmas. Mas ele não sabe! Assim que souber, contudo, não estaria sujeito a ser assimilado a uma cultura do negativo, do impossível e da resignação, na palavra, a uma cultura da sublimação?

Nos anos de 1980, anos de palavras de ordem, a experimentação singular das potências da imaginação e da alegria, no ensinar e no aprender, mas também no modo de se fazer política, parece-me terem ocupado um lugar tímido na hierarquia das prioridades pedagógicas e político-revolucionárias então reinantes, embora eu só viesse a me aperceber disso muito tempo depois. $\mathrm{Na}$ luta pela redemocratização do país, assunto também da maior gravidade, depois da anistia, o ensino e o aprendizado acadêmicos passavam pela participação, pela conscientização, pela militância, pela história, pela crítica, tendo em vista a reconquista da cidadania plena e a instituição de uma sociedade justa e igualitária. Diretrizes e valores propagados pela Teologia da Libertação e pela "Pedagogia do Oprimido" 
de Paulo Freire serviam de bússola e horizonte, humanistas, aos educadores engajados na educação popular, alimentando-os com esperança. A pedagogia crítico-social dos conteúdos encarnava, por assim dizer, o que Lúcia Aranha denominou de "otimismo dialético" na educação (Aranha, 1992). Marx e Hegel constituíam, pois, o horizonte do pensar e da prática progressistas e/ou revolucionários. Nessa perspectiva, a tarefa dos professores viu-se permeada por um misto de "catequese religioso-humanista" e engajamento crítico-progressista. Em paralelo, deu-se também o boom do construtivismo, reaquecido pelas contribuições de Emília Ferreiro e Ana Teberosky no campo da lecto-escrita; seguido de perto pela instituição da psicopedagogia como nova modalidade de prestação de serviços no campo educacional e pela recepção das idéias da psicologia sócio-histórica dos soviéticos. Como que em dissonância com essa atmosfera positiva e otimista, na qual reinavam polarizações ideológicas simplistas, certo "estruturalismo" insistia, ainda que tímida e tardiamente, em inquietar a mim, mas acredito que também àquelas palavras de ordem, por intermédio de um Foucault que já era outro - genealogista do poder - e por intermédio da psicanálise lacaniana, em vias de forte propagação e tranqüila aclimatação às terras tropicais.

Por sua vez, com os anos de 1990 sobrevêm a crise e um mal-estar difuso e generalizado, que acabaram por reverberar nas searas da educação. Com a queda do Muro de Berlim, com a revolução biotecno-informacional, com o desenvolvimento da telemática e da globalização, com a virtualização e aceleração do real, desfazem-se antigas e simplistas polarizações. $\mathrm{Na}$ política e, portanto, nas teorizações educacionais ditas críticas, sofre-se com o esgotamento do possivel, com o esvaziamento das utopias liberadoras e redentoras, apesar da explosão dos novos movimentos sociais e das ONGs. Teóricos, especialistas e professores sentem-se, pois, entre perdidos e confusos, em meio à multiplicidade e heterogeneidade de fluxos que inundam e trespassam seu cotidiano. $\mathrm{O}$ professor e o cidadão que este deveria formar, agora, convertem-se em performers e consumidores que, segundo Deleuze, só interessam ao sistema na medida em que estejam permanentemente endividados (Deleuze, 1992). A "nova educação" confunde-se com um misto de marketing e prestação de serviços, funcionando, inclusive, no regime de franquias. Psicologia, educação, auto-ajuda e técnicas de administração e de marketing, cada vez mais imbricadas entre si, perfazem novas tecnologias de gestão das subjetividades, que assediam cada vez mais o cotidiano das escolas e dos professores. 
De fardos que podem acompanhar a atividade docente ou de como o mestre...

Malgrado fale-se tanto em cidadania e participação, os novos valores superiores que animam a missão civilizadora da educação são aqueles emanados dos grandes conglomerados e das megacorporações empresariais. Inclusive, são eles próprios que incorporam esse discurso como estratégia de marketing, apresentando-se à sociedade como "instituiçôes" comprometidas e sensíveis às questôes sociais. Tudo isso contribui para a propagação de novas esquizofrenias entre os professores: "Sejam diferentes, sejam iguais". Doravante, cabe aos professores mostrarem-se "criativos" em classe, estando tal "criatividade", contudo, atrelada ao consumo e à utilização de métodos e/ou kits pedagógicos que o mercado educacional põe em circulação. Assim, embaraçados e envoltos em novos dilemas, os professores relutam entre os velhos e os novos modelos/valores que lhes são oferecidos. Ora, mas ao julgarem que o possível passa pela escolha seja dos primeiros, seja dos segundos, não estariam, ainda, optando por continuar a carregar fardos?

\section{À guisa de conclusão: da lógica de burros (ou camelos) e fardos}

Professores não são burros ou camelos, mas podem devir ("tornarse") um ou outro, conforme a maneira como agenciam seus encontros com a realidade, a alteridade, com seus pares, com práticas e discursos (inclusive psicopedagógicos), com o conhecimento, com seus alunos, com suas lutas políticas e, sobretudo, com a vida. Ora, o exercício da profissão de professor pode transformar-se num deserto, isto é, em algo insípido, sofrível, doloroso e frustrante, se submetido a valores ou entidades transcendentes, universais, abstratos (O Bem, O Mal, A Verdade, A Justiça, Deus etc.), dados de antemão, exteriores às relações concretas que eles efetivamente vivem nesta, com e por esta vida: a vida que de fato têm e experimentam, com suas delícias e seus dissabores, com suas alegrias e horrores. Devir burro (ou camelo) é agenciar-se à vida pela falta, pela carência, na medida em que os olhos, as aspirações, as motivações e referências para a ação se encontram aprisionados a entidades ou valores idealizados (puros modelos de perfeição), vinculados a um além da vida. Nesse movimento, a vida que efetivamente temos e levamos é desvalorizada (pois assumi-la consiste em carregar fardos) em proveito de outra, improvável, que sequer se pode nos dar à experiência. Seguindo esse raciocínio, não surpreende que ela, então, torne-se tão enfadonha, doente, ressentida, fadada a repetir-se monotonamente pela imitação do mesmo. Se o burro ou o camelo estão aqui associa- 
dos ao deserto, é porque fizeram e fazem de suas vidas essa enfadonha, cansativa e triste travessia, movida por uma vontade de nada, isto é, justamente por essa disposição que caracteriza o niilismo. Este, por seu turno, alimenta-se do ressentimento e estagna-se na paralisia: "É por tua culpa que me encontro nessa condição!", "Se não fosse por você, eu...!”. Nestes termos, devir burro, ou camelo, implica deixar-se tomar e guiar por atitudes reativas, sempre segundas (condicionadas a outras), o que caracteriza a incapacidade de afirmar a si mesmo e à vida com um Sim substancial, ativo, primeiro, vital - aquilo que Nietzsche chamava de amor fati. Porém qual a razão de o niilista (burro ou camelo) se quedar estagnado, tornando-se incapaz de movimentar-se e de agitar sua própria vida? É que, sob o domínio do medo e da amargura, acovardado, acomodado, acostumado em apenas repetir - por obrigação, por dever moral, por efeito de sua submissão a toda sorte de "valores superiores" - o que lhe disseram que era sensato, correto, bom, enfim, a seguir de acordo com o rebanho, ele já não possui discernimento do que pode, de suas potências, de suas próprias capacidades inventivas e de criação de valores. Para tanto, teria de abrir-se ao inusitado, ao imponderável, às contingências, à aventura mesmo de viver (e ensinar), o que só se torna possível por meio da experimentação, da criação e da invenção. Mas isso, entretanto, requereria dele disponibilidade para abandonar velhos hábitos, valores atemporais e ditos superiores, comodismos e "chaves do tamanho" (aquelas que supostamente abrem todas as portas), bem como disponibilidade para a coragem de correr riscos, ou seja, acolher e afirmar o sofrimento e a alegria que eles implicam, com eles aprendendo a conviver. Que os professores se disponham a isso: eis o desafio! Talvez, então, a cada pequeno acontecimento, a cada vez, a cada situação, a cada encontro, a cada devir-minoritário, ensinar e aprender possam ser reinventados e afirmados, mesmo que provisoriamente, mesmo que em sua finitude, em nome desta e por esta vida. Numa entrevista, Deleuze dizia que o problema não era ter de atravessar, mas nascer em desertos; ao que eu acrescentaria, "viver" e morrer neles sem tê-los experimentado.

Recebido em maio de 2005 e aprovado em julho de 2005.

\section{Referências bibliográficas}

ADORNO, T.W. Educação e emancipação. 2. ed. Rio de Janeiro: Paz \& Terra, 2000. 
De fardos que podem acompanhar a atividade docente ou de como o mestre...

ARANHA, L. Pedagogia histórico-critica: o otimismo dialético em educação. São Paulo: EDUC, 1992. (Contraponto)

CAMBI, F. História da pedagogia. São Paulo: UNESP, 1999. (Encyclopaidéia)

CAVESTANY, J.B. Daniel Defoe: grandeza e miséria de uma civilização. In: Lara, N.P.; Larrosa, J. (Org.). Imagens do outro. Petrópolis: Vozes, 1998. (Educação pós-crítica)

DELEUZE, G. Nietzsche. Lisboa: Edições 70, 1990. (Biblioteca básica de filosofia)

DELEUZE, G. Conversaçôes. Trad. Peter Pál Pelbart. São Paulo: Editora $34,1992$.

DELEUZE, G. Apêndice: Michel Tournier e o mundo sem outrem. In: Deleuze, G. Lógica do sentido. 2. ed. São Paulo: Perspectiva, 1998. p. 311-330.

GUIRADO, M. Instituição e relações afetivas: o vínculo com o abandono. São Paulo: Summus, 1986.

LARA, N.P.; LARROSA, J. Apresentação. In: Lara, N.P.; LARrosa, J. (Org.). Imagens do outro. Petrópolis: Vozes, 1998. (Educação póscrítica)

TODOROV, T. Nós e os outros: a reflexão francesa sobre a diversidade humana. V. 1. Rio de Janeiro: Jorge Zahar, 1993.

TOURNIER, M. Sexta-Feira ou os limbos do pacífico. 3. ed. Rio de Janeiro: Bertrand Brasil, 2001.

VALLE, L. A escola imaginária. Rio de Janeiro: DP\&A, 1997. 